\title{
Áreas de riesgo frente a temporal de mar en la provincia de Alicante
}

\author{
María Tros DE IlarduYA FernÁNDEZ \\ Universidad de Alicante \\ maria.tros@ua.es
}

Recibido: 16 de Febrero de 2011

Enviado a evaluar: 3 de Marzo de 2011

Aceptado: 23 de Marzo de 2012

\section{RESUMEN}

El impacto de los temporales de mar en la provincia de Alicante está condicionado por una serie de factores tanto físicos (morfologías y litologías, abrigo aerológico, batimetría, praderas de posidonia) como antrópicos (urbanización de la costa, ocupación de dunas, infraestructuras costeras). En el presente artículo se plantea la necesidad de emplear una escala extramunicipal para valorar adecuadamente el riesgo frente a los embates marinos.

Palabras clave: áreas de riesgo, temporal de mar, morfología costera, Posidonia oceanica, antropización, escala extramunicipal.

\section{Areas at risk of sea storm in the province of Alicante}

\begin{abstract}
The sea storms' impact on the province of Alicante is conditioned by a series of both physical (geomorphology and lithology, aerological shelter, bathymetry, posidonia prairies) and anthropic (coast urbanisation, dune occupation, coastal infrastructures) factors. In this article, the author expresses the need to use an extramunicipal scale in order to consider correctly the risk facing the sea battering.
\end{abstract}

Key words: risk areas, sea storm, coastal morphology, Posidonia oceanica, anthropization, extramunicipal scale. 


\title{
Zones à risques face à la tempête dans la province d'Alicante
}

\begin{abstract}
RÉSUMÉ
L'impact des tempêtes de mer sur le département d'Alicante est condittionné par une série de facteurs autant physiques (géomorphologie, lithologies, abri aérologic, bathymétrie, herbiers de posidonie) qu'anthropiques (urbanisation du littoral, occupation des dunes, infrastructures côtières). Dans cet article on expose la nécessité d'employer une échelle extra-communale afin d'apprécier correctement le risque face aux coups de mer.
\end{abstract}

Mots-clés: aléas, tempête de mer, morphologie côtière, Posidonia oceanica, anthropisation, échelle extra-communale.

\section{INTRODUCCIÓN}

El interés por el estudio de los espacios litorales no es reciente ${ }^{1}$. Desde siempre, el mar ha resultado tan fascinante como peligroso; fuente de vida y de misterio; alimento y dolor; calma y tempestad en el mismo ámbito. El mar, y las tierras emergidas próximas a él, suscitan el interés no sólo de sus moradores, sino de estudiosos e investigadores que tratan de comprender su dinámica y los mecanismos que vinculan tierra y agua. Las relaciones que el hombre mantiene con el mar no son siempre idílicas; en demasiadas ocasiones una ocupación indebida del territorio lleva a achacar a las fuerzas naturales acontecimientos y desgracias que podían haber sido, si no evitadas, al menos minimizadas.

El concepto de riesgo está asociado no sólo a la peligrosidad natural, sino a la vulnerabilidad de los asentamientos humanos poco acordes con el medio en el que se instalan. Por ello, el que una serie de episodios atmosférico-marinos de alta intensidad afecte de manera sistemática a una porción de territorio, no implica que ese espacio sea un área de riesgo frente a temporal de mar, si no es que las actividades humanas se ven perjudicadas.

\section{FACTORES GEOGRÁFICOS QUE CONDICIONAN EL RIESGO FRENTE A TEMPORAL DE MAR}

A lo largo de las últimas décadas, el impacto de los temporales de mar en la provincia de Alicante ha ido en aumento, a medida que ha aumentado el grado de urbanización de la costa. Sin embargo, se puede establecer una conclusión evidente: la morfología costera es fundamental a la hora de determinar el riesgo. Las áreas predominantemen-

${ }^{1}$ Se presenta en estas líneas el extracto de un capítulo de la tesis doctoral de su autora, titulada Incidencia de los temporales maritimos en el litoral de la provincia de Alicante. Políticas de actuación en materia de Ordenación del Territorio, realizada gracias a una beca predoctoral concedida por la Generalitat Valenciana y defendida en noviembre de 2008. 
te acantiladas -incluso las urbanizadas- han sufrido desperfectos de menor envergadura que aquéllas en las que predominan los procesos de sedimentación, como corrobora el hecho de que Les Rotes (Denia), el Tangó (Jávea), el Peñón de Ifach (Calpe) o Sierra Helada (Alfàs del Pi-Benidorm), por poner unos ejemplos, no se hayan visto apenas afectados. Sin embargo, numerosas playas -como el Arenal-Bol (Calpe), Poniente (Benidorm), o Muchavista-San Juan (Campello-Alicante)- han necesitado ser regeneradas y protegidas con campos de espigones, que no en todos los casos se han mostrado eficaces, como ha puesto de manifiesto la necesidad de remodelar la planta y disposición de los del Carrer la Mar (Campello), el litoral norte de Denia o las calas de Santiago Bernabéu (Santa Pola).

Pero con ser esencial el análisis de la morfología costera, existen otros elementos igualmente fundamentales para la determinación del riesgo. La combinación de todos estos factores dará como resultado la existencia de espacios de riesgo más o menos elevado frente a temporales de mar.

Un elemento que no por evidente deja de ser significativo es la exposición de la línea de costa a los diferentes flujos (aéreos y marinos). El vínculo entre la orientación geográfica de los tramos costeros y los flujos que presentaron consecuencias territoriales más perniciosas está muy claro. Aunque los vientos de mayor longitud de fetch son los procedentes de levante, y buena parte de la costa de la provincia está orientada en esa dirección, cabe señalar la existencia de sectores protegidos de manera natural frente a esas componentes y que, sin embargo, registran daños de entidad con oleajes generados por vientos de otros hogares. En este sentido, hay que insistir en la influencia que ejercen los obstáculos naturales (cabos, islas) y artificiales (diques, espigones) bien en la protección de la línea de costa o bien, por el contrario, en la generación de un nuevo espacio de riesgo. Así, por ejemplo, el macizo de Sierra Helada presta socorro a las playas benidormenses frente a los vientos de levante, mientras que el Cabo de Santa Pola hace lo propio respecto a los flujos del N, que no afectan en ninguna medida a las playas santapoleras. Por el contrario, la presencia de infraestructuras portuarias suele ser perjudicial para las playas ubicadas a sotacorriente, como se evidencia en El Albir (Alfàs del Pi) debido a la zona de sombra proyectada por el dique de abrigo del puerto de Altea, ubicado aguas arriba; o en la playa del Carrer la Mar, situada justo al sur del puerto de Campello.

Podría afirmarse, entonces, que no existen "sectores de riesgo" en general, sino "sectores de riesgo en relación con la componente del viento" que genera un oleaje. De esa manera, habrá áreas de riesgo frente a levantes, sirocos, o gregales, por ejemplo; o, ampliando por cuadrantes el origen de esos flujos, áreas de riesgo frente a vientos del primer, segundo o tercer cuadrante. Por lo tanto, es necesario, y no sólo deseable, disponer de un Banco de Datos Oceanográfico mucho más completo del que en la actualidad ofrece Puertos del Estado, para lo cual resulta imprescindible aumentar las redes de medida y registro del oleaje, con el objeto de determinar el hogar del que proceden los trenes de olas que afectan a sectores de orientación geográfica muy dispar. El análisis de la repercusión de los temporales de mar en función de la exposición de la costa evidencia que no es posible extrapolar los valores de una boya 
determinada a otras áreas alejadas, especialmente si éstas se encuentran al socaire de las componentes registradas.

A la morfología costera y a la orientación de la línea de costa se une otro factor importante, tal que la granulometría de los áridos que conforman las playas. En episodios de mal estado de la mar, los propios cantos y bolos alojados en la playa son lanzados por el oleaje contra paseos marítimos y edificaciones, intensificando su poder destructivo. Sirvan como ejemplo las playas de La Roda (Altea), playa Centro (La Vila Joiosa) o Carrer la Mar (Campello). Las regeneraciones, con las que se ha sustituido estos materiales de diámetro grueso por arenas, han permitido mitigar la repercusión del oleaje sobre estos espacios afectados, aunque al ser áridos más finos y ligeros, son arrancados por las olas con mayor facilidad.

Por otra parte, la mayor parte del litoral alicantino se encuentra ya urbanizado, principalmente en sus costas bajas, pero también en las acantiladas, a excepción de pequeños tramos expeditos de edificaciones, como Sierra Helada, Sierra de Castilla, Lomas de Rejas o la playa de Higuericas. Las costas arenosas con un alto grado de urbanización son las que se revelan más propicias a sufrir daños de consideración en episodios de temporal de mar, como se evidencia en la bahía de Jávea, los sectores urbanos de Calpe y Altea, el ensanche de Santa Pola o el núcleo urbano de Torrevieja.

La mayor parte de los antiguos cordones dunares del litoral alicantino ha sido devastada por la urbanización, hecho perfectamente legal hasta la entrada en vigor de la Ley 22/88 de Costas, pues en la legislación anterior las dunas no tenían consideración de dominio público marítimo-terrestre. La ocupación urbana de esos primitivos cordones dunares ha favorecido igualmente la aparición del riesgo, como queda patente al analizar las repercusiones de los temporales marinos en los sectores de Arenales del Sol-Urbanova o El Pinet. En la mayor parte de estas unidades, las dunas se conservan en un estado óptimo que favorece el intercambio eólico de áridos con la playa. No obstante, en algunas porciones de esos espléndidos tramos dunares -que en teoría garantizan una playa extensa y en perfectas condiciones-, esa alimentación continental se ha visto interrumpida por la presencia de edificaciones en Dominio Público que actúan a modo de pantalla (tal como sucede con las viviendas situadas en la playa de la Babilonia, en Guardamar; y también en El Pinet, en el litoral meridional de Elche), por lo que, en esos sectores de ocupación poco apropiada del territorio, es precisamente donde la playa se encuentra en franca regresión, hasta el punto de que los edificios se ven alcanzados por las olas.

La intensa regulación de los ríos, e incluso la urbanización de cauces secos y barrancos, cuyos materiales susceptibles de arrastre son así eliminados del sistema, repercute en la mengua de sedimentos que alcanzan la costa para ser redistribuidos longitudinalmente por las corrientes, por lo que muchas playas ven reducida de esa manera su alimentación. Si bien Sanjaume (1985) considera las costas arenosas como ámbitos de acumulación, en gran parte de los arenales de la provincia de Alicante se produce, por el contrario, una intensa erosión, principalmente durante episodios de temporal de mar -incluso con aquéllos de intensidad moderada-, erosión inducida por actuaciones antrópicas poco acordes con los agentes de la dinámica marina. 
Otro factor que hay que tener en cuenta es la presencia, bajo las aguas del Mediterráneo, de verdaderos bosques de fanerógamas marinas, entre las que destaca la Posidonia oceanica, una especie endémica que se instala preferentemente en fondos arenosos, aunque también puede hacerlo sobre roca, extendiéndose desde la superficie hasta una profundidad máxima de cincuenta metros en función de la calidad y la turbidez de las aguas. Las praderas de Posidonia modifican los procesos sedimentarios y la propagación del oleaje sobre la plataforma continental, por lo que resultan fundamentales en la formación o desaparición de las playas. Las praderas submarinas tienen un papel muy activo en la dinámica litoral, desde el momento en que las hojas actúan como parapeto y hacen precipitar los sedimentos suspendidos en el agua. Los rizomas y raíces retienen estos sedimentos y los incorporan al sustrato, de tal manera que el fondo se va elevando progresivamente, no sólo gracias a los aportes sedimentarios estabilizados, sino también a los rizomas y hojas muertas de la propia planta. Las praderas no quedan sepultadas bajo los sedimentos que retienen debido a que los rizomas pueden crecer verticalmente. Esta particularidad hace que las praderas formen estructuras verticales de rizomas y sedimentos denominadas terrazas. La pradera forma, asimismo, unas estructuras longitudinales cercanas a la superficie marina y paralelas a la costa -denominados arrecifes-barrera-, que pueden elevarse un centímetro al año en condiciones ambientales favorables. Estas murallas subacuáticas frenan la energía del oleaje que incide sobre las playas. Tal y como señala Coque (1984) -y otros autores, como Ortiz (2004)-, existe una relación entre la profundidad del fondo marino (d) y la longitud de onda ( $\lambda$ ), de tal suerte que la energía de la ola comienza a disiparse cuando la distancia con el fondo es igual o inferior a la mitad de la longitud existente entre dos crestas consecutivas $(\mathrm{d} \leq \lambda / 2)$. Por lo tanto, cuanto más desarrollada en la vertical se encuentre la pradera de fanerógamas, antes "sentirá el fondo" la ola y con mayor presteza comenzará a perder velocidad, llegando más atenuada a la línea de costa. Actuaciones como la construcción de puertos deportivos y espigones, la regeneración de playas, los colectores y dragados, entre otras, destruyen las características ambientales de su hábitat, pues implican tanto un aumento en la turbidez de las aguas como cambios en la dinámica marina y, por lo tanto, modificación de los procesos de erosión y sedimentación. La consecuencia es la regresión de las praderas. Uno de los principales problemas para la protección de la Posidonia es la falta de cartografía de su estado de salud y de su localización y extensión exacta, para poder determinar su evolución. Existen, es cierto, trabajos parciales y recopilaciones más o menos actualizadas, con diferente grado de precisión. Pese a ello, el conocimiento exhaustivo de su extensión real resulta clave para proceder a una defensa adecuada.

Al expandirse los sectores urbanos, algunos espacios han devenido de riesgo en las últimas décadas; sin embargo, en este trabajo no se plantea la evolución del riesgo en las últimas décadas, sino la existencia de áreas de riesgo en la actualidad, con el fin de que las Administraciones puedan emprender desde este momento medidas de mejora y corrección frente a la adversidad marina. Y ello, porque las tareas de planificación y ordenación del territorio deben basarse en el conocimiento del pasado para adecuarse al presente y planificar el futuro. 


\section{VALORACIÓN DE LAS ÁREAS DE RIESGO FRENTE A TEMPORAL DE MAR EN EL LITORAL ALICANTINO}

Atendiendo a todos los parámetros físicos y antrópicos arriba señalados se ha elaborado la Tabla 1, en la que se refleja aquellos tramos costeros de la provincia de Alicante, por municipios ordenados de norte a sur, que han sufrido un mayor grado de deterioro como consecuencia del mal estado de la mar. Espacios con un grado elevado o medio de ocupación humana que, bien frecuente, bien ocasionalmente, pueden sufrir graves deterioros motivados por el oleaje, son los que se conciben en este artículo como "áreas de riesgo" frente a temporales marinos.

A primera vista, puede percibirse que se trata en su mayor parte de tramos de costa baja y puertos, aunque al valorar la repercusión del oleaje en estos últimos se ha englobado no sólo los desperfectos en las propias instalaciones portuarias, sino también todas las actividades relacionadas con la pesca y la náutica deportiva, de tal forma que un estado adverso de la mar puede haber motivado el amarre de toda una flota, con lo que ello supone de calamitoso para algunas economías locales. La valoración general se ha sintetizado visualmente en los mapas correspondientes a la definición de áreas de riesgo del litoral alicantino (mapas 1 a 4). Por motivos de claridad gráfica, se ha dividido la provincia de Alicante en cuatro sectores, ordenados de nuevo de norte a sur, y representados a escala 1:200.000.

Tabla 1. Principales áreas de riesgo frente a temporal de mar

\begin{tabular}{|c|c|c|c|c|c|c|c|}
\hline \multicolumn{2}{|c|}{$\begin{array}{c}\text { PRINCIPALES ESPACIOS } \\
\text { AFECTADOS }\end{array}$} & \multirow{2}{*}{$\begin{array}{c}\text { EXP. AL } \\
\text { VIENTO } \\
1^{\text {er }} \text { cuadrante }\end{array}$} & \multirow{2}{*}{$\begin{array}{l}\text { MORF. } \\
\text { COST. } \\
\text { C. baja }\end{array}$} & \multirow{2}{*}{\begin{tabular}{|c|} 
DUNAS \\
No \\
\end{tabular}} & \multirow{2}{*}{$\begin{array}{l}\text { GRADO DE } \\
\text { URB. } \\
\text { Alto }\end{array}$} & \multirow{2}{*}{$\begin{array}{l}\text { PUERTO } \\
\text { A } \\
\text { BARLOC } \\
\text { No }\end{array}$} & \multirow{2}{*}{$\begin{array}{c}\text { GRADO } \\
\text { RIESGO } \\
\text { Alto } \\
\end{array}$} \\
\hline Els Poblets & L'Almadrava & & & & & & \\
\hline \multirow{5}{*}{ Denia } & Les Deveses & $1^{\mathrm{er}}$ cuadrante & C. baja & No & Alto & No & Alto \\
\hline & L'Almadrava & $1^{\mathrm{er}}$ cuadrante & C. baja & No & Alto & No & Alto \\
\hline & Les Marines & $1^{\mathrm{er}}$ cuadrante & C. baja & No & Alto & No & Alto \\
\hline & Marineta Cassiana & $1^{\text {er }}$ cuadrante & C. baja & No & Alto & Sí & Alto \\
\hline & Puerto & $1^{\text {er }}$ cuadrante & - & No & - & - & Alto \\
\hline \multirow{5}{*}{ Jávea } & Tangó & $1^{\text {er }}$ cuadrante & Acantil. & No & Bajo & No & Medio \\
\hline & La Grava & $1^{\text {er }}$ cuadrante & C.baja & No & Alto & Sí & Alto \\
\hline & Benissero & $1^{\text {er }}$ cuadrante & C. baja & No & Alto & Sí & Alto \\
\hline & L'Arenal & $1^{\text {er }}$ cuadrante & C. baja & No & Alto & No & Alto \\
\hline & Puerto & $1^{\text {er }}$ cuadrante & - & No & - & - & Alto \\
\hline Benitatxell & Cala del Moraig & $\mathrm{E}$ & Acantil. & No & Bajo & No & Medio \\
\hline \multirow{2}{*}{ Teulada } & L'Ampolla & $\mathrm{E}$ & C. baja & No & Medio & Sí & Alto \\
\hline & El Portet & SW & C.baja & No & Medio & No & Medio \\
\hline Benissa & Fustera & SE & C.baja & No & Bajo & No & Medio \\
\hline \multirow[t]{2}{*}{ Calpe } & $\begin{array}{l}\text { La Fossa o } \\
\text { Levante }\end{array}$ & $1^{\text {er }}$ cuadrante & C. baja & No & Alto & No & Alto \\
\hline & Arenal-Bol & SW & C. baja & No & Alto & Sí & Alto \\
\hline \multirow{2}{*}{ Calpe } & Puerto & SW & - & No & - & - & Alto \\
\hline & El Racó & SW & C.baja & No & Bajo & No & Medio \\
\hline
\end{tabular}




\begin{tabular}{|c|c|c|c|c|c|c|c|}
\hline \multirow{2}{*}{ Altea } & La Roda & E & C.baja & No & Alto & No & Alto \\
\hline & Puerto & $\mathrm{E}$ & - & No & - & - & Alto \\
\hline L'Alfàs del Pi & El Albir & $\mathrm{E}$ & C.baja & No & Alto & Sí & Alto \\
\hline \multirow{3}{*}{ Benidorm } & Levante & $3^{\text {er }}$ cuadrante & C.baja & No & Alto & No & Alto \\
\hline & Puerto & $3^{\text {er }}$ cuadrante & - & No & - & - & Alto \\
\hline & Poniente & $2^{\circ}$ y $3^{\text {er }}$ cuadrante & C.baja & No & Alto & Sí & Alto \\
\hline Finestrat & Cala de Finestrat & $2^{\circ}$ cuadrante & C. baja & No & Medio & No & Medio \\
\hline La Vila Joiosa & Playa Centro & $\mathrm{E}$ & C. baja & No & Alto & Sí & Alto \\
\hline Campello & Carrer la Mar & $1^{\mathrm{er}}$ y $2^{\circ}$ cuadrante & C. baja & No & Alto & Sí & Alto \\
\hline Campello & Muchavista & $1^{\mathrm{er}}$ y $2^{\circ}$ cuadrante & C. baja & No & Alto & No & Alto \\
\hline Alicante & Playa de S. Juan & $1^{\mathrm{er}}$ y $2^{\circ}$ cuadrante & C. baja & No & Alto & No & Alto \\
\hline Alicante & Albufereta & $2^{\circ}$ y $3^{\text {er }}$ cuadrante & C. baja & No & Alto & Sí & Alto \\
\hline \multirow{2}{*}{ Alicante } & Postiguet & $1^{\mathrm{er}}$ cuadrante & C. baja & No & Alto & No & Alto \\
\hline & Tabarca & $1^{\mathrm{er}}$ y $2^{\circ}$ cuadrante & C. baja & No & Medio & No & Medio \\
\hline Elche $(\mathrm{N})$ & Arenales del Sol & $1^{\mathrm{er}}$ cuadrante & C. baja & Sí & Alto & No & Alto \\
\hline \multirow{2}{*}{ Santa Pola } & Santa Pola E & $\mathrm{E}$ & $\begin{array}{l}\text { C. baja } \\
\text { (rocosa) }\end{array}$ & No & Alto & No & Medio \\
\hline & Santiago Bernabéu & $2^{\circ}$ y $3^{\text {er }}$ cuadrante & $\begin{array}{c}\text { C. baja } \\
\text { (rocosa) }\end{array}$ & No & Alto & No & Medio \\
\hline \multirow{3}{*}{ Santa Pola } & Puerto & $2^{\circ}$ y $3^{\text {er }}$ cuadrante & - & No & - & - & Alto \\
\hline & Gran Playa & $2^{\circ}$ y $3^{\text {er }}$ cuadrante & C. baja & No & Alto & Sí & Alto \\
\hline & Playa Lissa & $2^{\circ}$ y $3^{\mathrm{er}}$ cuadrante & C. baja & No & Alto & Sí & Alto \\
\hline Elche (S) & El Pinet & $1^{\text {er }}$ y $2^{\circ}$ cuadrante & C. baja & Sí & $\begin{array}{c}\text { Bajo } \\
\text { (excepto } \\
\text { tramo) }\end{array}$ & No & $\begin{array}{c}\text { Alto en } \\
\text { tramo } \\
\text { edificado } \\
\text { Bajo en el } \\
\text { resto }\end{array}$ \\
\hline \multirow[t]{2}{*}{ Guardamar } & Babilonia & $1^{\mathrm{er}}$ y $2^{\circ}$ cuadrante & C. baja & Sí & $\begin{array}{c}\text { Bajo } \\
\text { (excepto } \\
\text { tramo) }\end{array}$ & Sí & $\begin{array}{c}\text { Elevado en } \\
\text { el tramo } \\
\text { edificado } \\
\text { Bajo en el } \\
\text { resto }\end{array}$ \\
\hline & Moncayo & $1^{\text {er }}$ y $2^{\circ}$ cuadrante & C. baja & Sí & Bajo & No & Medio \\
\hline \multirow{4}{*}{ Torrevieja } & La Mata & $1^{\mathrm{er}}$ y $2^{\circ}$ cuadrante & C. baja & Tramo & Alto & No & Alto \\
\hline & Los Locos & $2^{\circ}$ y $3^{\text {er }}$ cuadrante & C. baja & No & Alto & No & Alto \\
\hline & Del Cura & $2^{\circ}$ y $3^{\text {er }}$ cuadrante & C. baja & No & Alto & No & Alto \\
\hline & Puerto & $2^{\circ}$ y $3^{\text {er }}$ cuadrante & - & No & - & - & Alto \\
\hline \multirow{4}{*}{ Orihuela } & Punta Prima & $1^{\text {er }}$ y $2^{\circ}$ cuadrante & C. baja & No & Medio & No & Medio \\
\hline & Playa Flamenca & $1^{\mathrm{er}}$ cuadrante & C. baja & No & Medio & No & Medio \\
\hline & Cabo Roig & $1^{\mathrm{er}}$ cuadrante & C. baja & No & Medio & Sí & Medio \\
\hline & Campoamor & $1^{\text {er }}$ cuadrante & C. baja & No & Medio & No & Medio \\
\hline $\begin{array}{l}\text { El Pilar } \\
\text { Horadada }\end{array}$ & El Mojón & $\mathrm{E}$ & C. baja & No & Alto & No & Alto \\
\hline
\end{tabular}

Sectores de riesgo medio

Sectores de riesgo variable según presencia de edificación

Fuente: Elaboración propia 


\subsection{DELIMITACIÓN DE ÁREAS DE RIESGO ENTRE ELS POBLETS Y ALTEA}

Las costas bajas del litoral norte de Denia (Mapa 1) muestran una respuesta similar frente a temporales de mar. Por su exposición y alto grado de urbanización, puede decirse que representan un sector de riesgo elevado en episodios con flujos procedentes del primer cuadrante, con los que han experimentado daños destacables.

Mapa 1. Delimitación de áreas de riesgo frente a temporales de mar (Els Poblets - Altea)

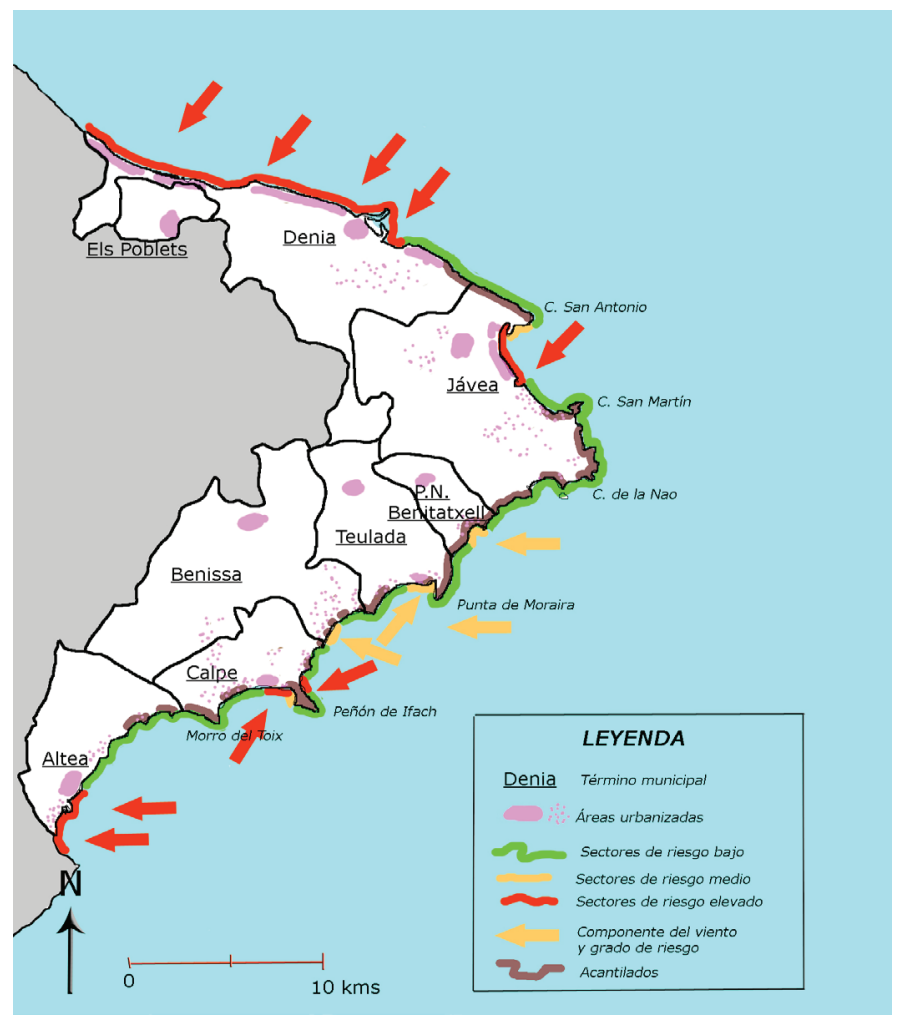

Fuente: Elaboración propia

Sin embargo, el litoral acantilado de Les Rotes apenas registra desperfectos, y ha sido catalogado como sector de riesgo bajo.

Junto al tramo más urbanizado del municipio de Jávea se extienden las playas de La Grava, Benissero y L'Arenal, y también el puerto, que son especialmente sensibles frente a vientos del primer cuadrante y han sido clasificados como sectores de riesgo elevado frente a oleajes generados por vientos de esta componente.

El litoral comprendido entre el Cabo San Martín y la Punta de Moraira está constituido por acantilados. De escaso grado de ocupación antrópica, presenta también un respuesta homogénea frente a los temporales marinos y un nivel bajo 
de riesgo. Sólo la Cala del Moraig (P.N. de Benitatxell), que cuenta con un aparcamiento descalzado por las olas en alguna ocasión, y algunas infraestructuras que dan servicio a los bañistas, ha sido considerada como sector de riesgo medio frente a flujos de levante, principalmente.

El litoral de acantilados bajos de Teulada y Benissa, ha sido clasificado en general como área de riesgo bajo. No obstante, destacan en él algunos núcleos urbanizados, como El Portet de Moraira, marcado como de riesgo medio frente a vientos del SW; o L'Ampolla, frente a vientos de levante. La cala Fustera se muestra susceptible de perder arenas y dotaciones playeras con oleajes del SE y ha sido entendida como área de riesgo medio frente a flujos de esa componente.

La playa calpina de La Fossa, orientada a levante y con un alto grado de urbanización, se entiende como área de riesgo elevado frente a vientos del primer cuadrante. Al otro lado del Peñón de Ifach, con una orientación que difiere de la del sector anterior, el puerto de Calpe y la playa del Arenal-Bol son también espacios de riesgo elevado, esta vez frente a flujos del SW. La pequeña playa del Racó, generada por la acumulación de sedimentos inducida por la presencia del dique de abrigo del puerto, se muestra también vulnerable frente a oleajes generados con vientos del SW, pero el grado de urbanización no es elevado, y por ello se considera un sector de riesgo medio.

La costa de acumulación de los municipios de Altea y L'Alfàs del Pi presenta también homogeneidad en su caracterización como sector de riesgo elevado frente a oleajes generados por vientos de levante. Las playas urbanas de La Roda y El Albir pierden áridos con mucha frecuencia y sufren grave deterioro en equipaciones y mobiliario playero como consecuencia del embate de las olas. El puerto de Altea, en el que se desarrollan actividades pesqueras y deportivas, ha sido incluido también como área de riesgo elevado. La presencia del puerto repercute en la pérdida de arenas de la playa de El Albir, situada a sotacorriente, y en una mayor incidencia de los temporales marinos.

\subsection{DELIMITACIÓN DE ÁREAS DE RIESGO ENTRE L'ALFÀS DEL PI Y CAMPELLO}

El área de acantilados de Sierra Helada (Mapa 2), compartida por los municipios de L'Alfàs del Pi y Benidorm, espacio natural protegido y expedito por ello de edificaciones y otras formas de aprovechamiento, ha sido concebida como sector de riesgo bajo frente a temporales marinos; no así la bahía benidormense, orientada al S y con un altísimo grado de urbanización. Los flujos que con más dureza afectan a las playas de Levante y Poniente, e igualmente al puerto, son los procedentes del segundo y el tercer cuadrantes, es decir, aquéllos en los que está presente una componente meridional. El nivel de ocupación antrópica de la próxima Cala de Finestrat es menos elevado que en la bahía de Benidorm, por lo que puede entenderse ese sector como de riesgo medio, también frente a flujos del segundo cuadrante. 
Mapa 2. Delimitación de áreas de riesgo frente a temporales de mar (L’Alfàs del Pi-Campello)

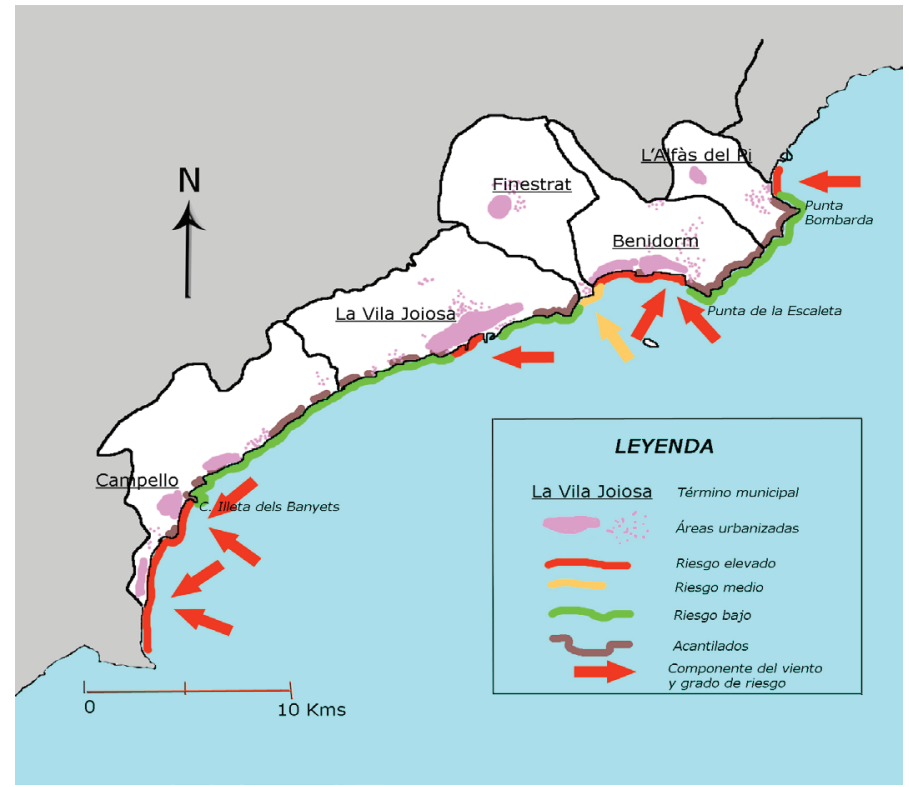

Fuente: Elaboración propia.

Todo el litoral de acantilados medios y bajos de La Vila Joiosa y Campello es considerado como área de riesgo bajo frente a temporales marinos. Los escasos desperfectos recogidos por la prensa en las tres últimas décadas así lo sugieren.

Sin embargo, a modo de "isla" en todo este tramo, la costa urbana de La Vila Joiosa, se entiende como área de riesgo elevado frente a vientos de levante, generadores de oleajes que resultan en extremo perjudiciales para el puerto y la Playa Centro y las actividades humanas que se asientan en sus inmediaciones.

Los sectores de acumulación del Carrer La Mar y Muchavista (Campello), y su prolongación hacia el sur en la alicantina Playa de San Juan, presentan igualmente uniformidad en su catalogación como áreas de riesgo elevado frente a oleajes generados por vientos del primer y segundo cuadrante. Su exposición a levante, su naturaleza abierta, y su altísimo grado de urbanización, convierten a este tramo de costa en uno de los más castigados por los temporales de mar de toda la provincia.

\subsection{DELIMITACIÓN DE ÁREAS DE RIESGO ENTRE ALICANTE Y GUARDAMAR}

El tramo de acantilados del Cabo de las Huertas (Mapa 3) ha sido comprendido como sector de riesgo bajo en episodios de mal estado de la mar. No obstante, por su exposición al S, por su alto grado de urbanización, y por la presencia a barlocorriente de 
un puerto deportivo que modifica la deriva litoral, la zona de la Albufereta ha sido delimitada como área de riesgo elevado frente a flujos del segundo y el tercer cuadrante.

Mapa 3. Delimitación de áreas de riesgo frente a temporales de mar (Alicante - Guardamar)

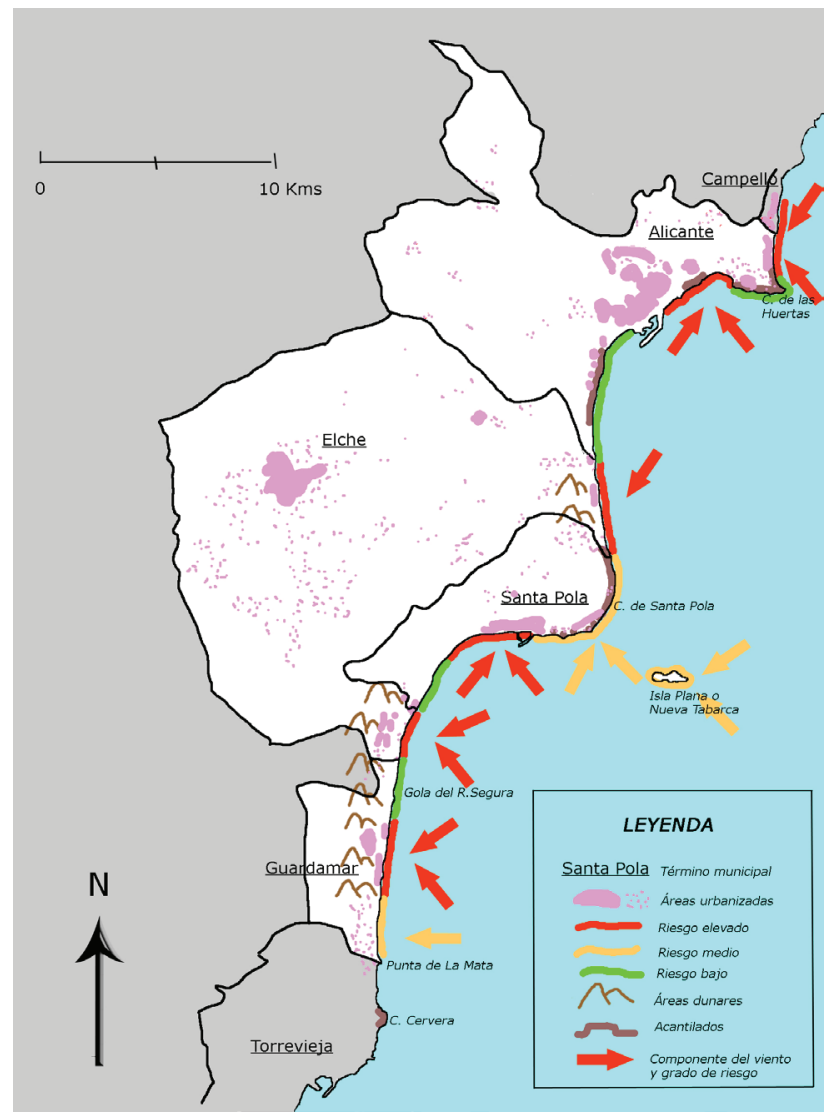

Fuente: Elaboración propia

La playa urbana de Alicante, El Postiguet (orientada al E), y todas las actividades que junto a ella tienen lugar, se ha visto muy afectada, sin embargo, por vientos del primer cuadrante o que incorporan la componente levantina. La isla de Tabarca, aunque alejada espacialmente del término de Alicante, está gestionada por este Ayuntamiento. Su grado de urbanización no es demasiado elevado, pero su carácter plano, sin ningún obstáculo que sirva de abrigo, y la exposición de su puerto, hacen especialmente vulnerables las comunicaciones con la península en episodios de temporal de mar desencadenado con vientos del primer y segundo cuadrante. Ha sido considerada como un área de riesgo medio. 
El litoral septentrional de Elche, a pesar de contar con un cordón dunar bien desarrollado, que facilita los aportes de áridos continentales a la playa, ha sido definido como un área de riesgo alto frente a flujos del primer cuadrante. La exposición a levante de todas las playas de este sector -desde El Saladar de Aigua Amarga, pasando por Urbanova, hasta las inmediaciones del Cabo de Santa Pola-, se suma a su configuración abierta y a la existencia de algunos tramos altamente antropizados, que son los que le confieren su elevado nivel de riesgo.

Los acantilados bajos del Cabo de Santa Pola, a pesar de encontrarse urbanizados, no sufren graves desperfectos en episodios de temporal de mar. Las calas de Santa Pola del E representan un riesgo medio frente a la componente levantina, mientras que las calas de Santiago Bernabéu y el puerto, orientados al S, sufren daños de grado medio con flujos procedentes del segundo y del tercer cuadrante.

El alto grado de urbanización del ensanche santapolero, que se extiende hacia el $\mathrm{W}$ de la ciudad, es el desencadenante de un riesgo elevado en los sectores del puerto, Gran Playa y Playa Lisa, vulnerables principalmente ante oleajes generados con vientos del segundo y del tercer cuadrante. La presencia del puerto a barlocorriente incide negativamente sobre las playas, que en episodios de temporal de mar pierden áridos que no son devueltos posteriormente al sistema, llegando a alcanzar el oleaje las edificaciones de primera línea.

El sector que abarca las extensas áreas dunares comprendidas entre Santa Pola, Elche meridional y Guardamar, no muestra en este caso una respuesta homogénea frente a temporales marinos, a pesar de su naturaleza abierta y de encontrarse orientado claramente a levante. Se suceden, así, áreas de riesgo bajo y otras de riesgo elevado o medio -coincidentes estas últimas con las áreas urbanizadas de El Pinet, la Babilonia y el Moncayo- frente a flujos del primer y segundo cuadrante, que se revelan como aquéllos de efectos más perniciosos. Las playas ven mermada su anchura sólo en aquellos tramos en los que la presencia de las edificaciones actúa como pantalla en el transporte eólico de sedimentos.

\subsection{DELIMITACIÓN DE ÁREAS DE RIESGO ENTRE TORREVIEJA Y EL PILAR DE LA HORADADA}

La playa de La Mata (Torrevieja) presenta sin embargo un alto grado de ocupación antrópica, y ello a pesar de que se conserva un pequeño sector de duna, integrado en la trama urbana, que no resulta suficiente para compensar las pérdidas de áridos del sistema. El riesgo se ha definido aquí como elevado (Mapa 4) frente a flujos del primer y del segundo cuadrante que, por la orientación de la línea de costa, son los que inciden de manera más activa. 
Mapa 4. Delimitación de áreas de riesgo frente a temporales de mar (Torrevieja - El Pilar de la Horadada)

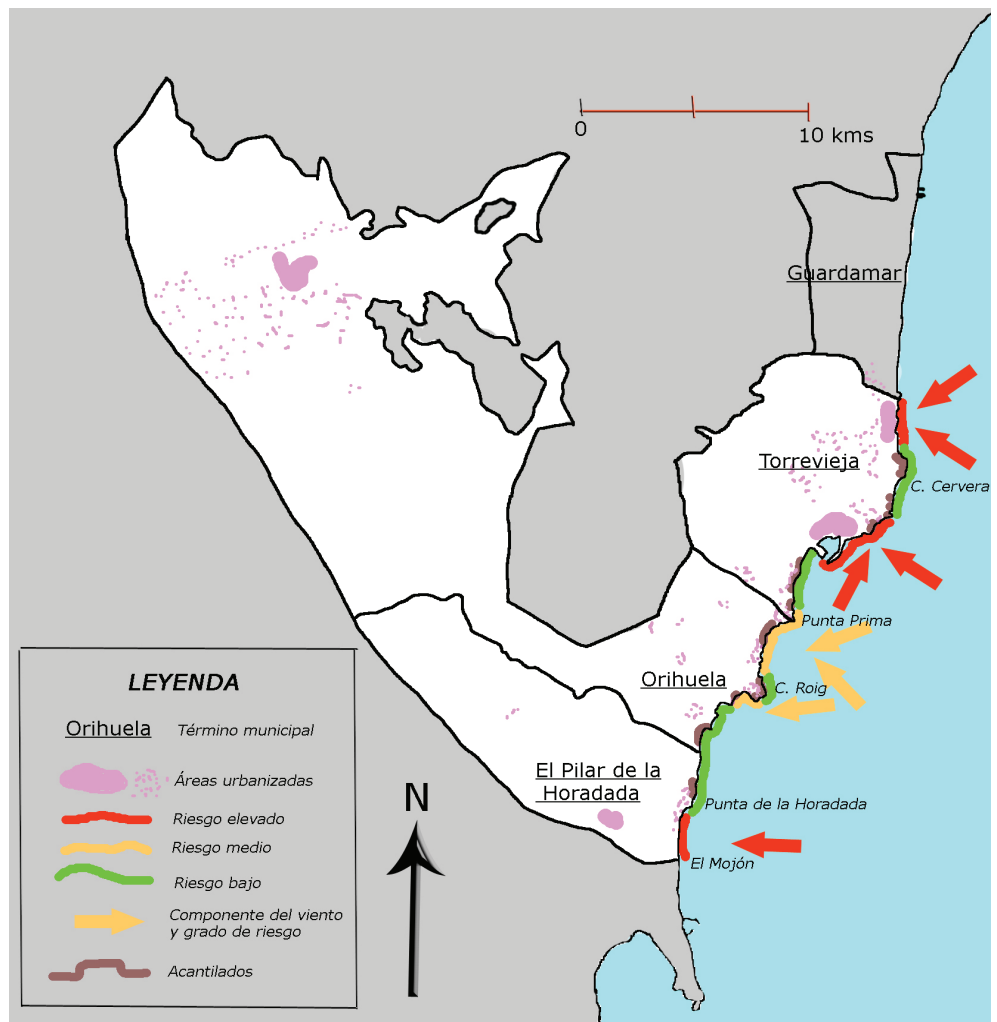

Fuente: Elaboración propia

Los acantilados bajos del Cabo Cervera se consideran sector de riesgo bajo frente a temporales de mar; al contrario de lo que sucede en el tramo adyacente al puerto de Torrevieja, así como en las playas urbanas de Los Locos y El Cura, espacios muy urbanizados y claramente susceptibles de sufrir daños con flujos del segundo y el tercer cuadrantes. Han sido definidos, por ello, como área de riesgo elevado.

Desde el sector urbano de Torrevieja hasta el S de la provincia, en el límite con la Región de Murcia, se alternan tramos de costa erosiva con otros de sedimentación, con un nivel medio de ocupación humana. Punta Prima es un sector de riesgo medio frente a oleajes generados con vientos del primer y segundo cuadrante. El primer cuadrante es el que está presente en la catalogación como áreas de riesgo medio de Playa Flamenca, Cabo Roig o Campoamor.

Sólo el punto más meridional de El Pilar de la Horadada, conocido como El Mojón, presenta un nivel elevado de ocupación antrópica y un nivel alto de riesgo en episodios de temporal marino en los que soplan vientos de levante. 


\section{CONCLUSIONES}

Como se ha visto en las líneas precedentes, el manejo del concepto administrativo de municipio no resulta operativo a la hora de determinar el alcance del riesgo en los diferentes episodios de temporal de mar, por las razones que se esgrimen a continuación.

El concepto de riesgo, definido desde los años 70 y 80 por autores como Calvo (1982) -y posteriormente por Olcina (1997) y otros (Vera, 2002; Torres, 2002)- como la potencialidad de que un fenómeno natural tenga incidencia sobre un territorio ocupado por actividades antrópicas, implica un doble factor: la peligrosidad natural y la vulnerabilidad humana. Por este motivo, el mayor o menor grado de ocupación humana del litoral influirá claramente en la valoración de los efectos de los temporales. El municipio que dispone de muchos kilómetros de costa, pero con escaso asentamiento de actividades humanas, sufrirá daños de menor cuantía que el municipio que tiene menos kilómetros, pero intensamente ocupados. Recordemos que es la ocupación del territorio poco acorde con las características del medio lo que transforma el litoral en un área de riesgo.

En relación con ello, conviene exponer que no puede equipararse un municipio que tiene varios kilómetros de costa con otro que sólo dispone de unos cientos de metros. A mismo grado de urbanización, el primer municipio estará mucho más expuesto a los flujos y sufrirá, en teoría, mayores daños en el cómputo global que el segundo.

Igualmente, cabe recordar la posibilidad de que, en esos miles de metros, la disposición de la línea de costa sea muy heterogénea -Calpe es un buen ejemplo, por estar orientado al este y al sur, según sea el tramo analizado-, por lo que el municipio se verá afectado por flujos de componentes muy diversas, de tal forma que los distintos sectores de costa pueden responder de manera diferente en un mismo episodio.

Tampoco la totalidad de la línea de costa de un municipio está protegida de la misma manera por las praderas de Posidonia oceanica. Los algueros se ubican principalmente en sectores de naturaleza acantilada y profunda batimetría, allí donde no existe un exceso de sedimento que les impide realizar la fotosíntesis; y a esto se suma la circunstancia de que su estado de salud no es uniforme a lo largo de todo el litoral.

Por último, resulta fundamental argüir que ni las morfologías costeras ni las litologías tienen por qué ser uniformes en la totalidad de un municipio. Las repercusiones de un temporal sobre playas de arena o gravas; o sobre un acantilado o una costa baja -unidades que pueden estar presentes en unos pocos kilómetros englobados bajo la misma entidad administrativa- no son semejantes.

Por lo tanto, para abordar la delimitación del riesgo, más apropiado que hablar de "municipios" en términos generales, conviene emplear una escala territorial que aglutine unidades de naturaleza física similar, unidades cuya extensión -que puede ser extremadamente dispar- sea susceptible de abarcar el tramo litoral completo de un municipio o sólo una parte de él; o pueda incluso trascender los límites administrativos y englobar sectores que pertenezcan a dos o más municipios distintos. 


\section{BIBLIOGRAFÍA}

CALVO GARCÍA-TORNEL, F. (1982): El riesgo, un intento de valoración geográfica, Academia Alfonso X el Sabio, Murcia.

CALVO GARCÍA-TORNEL, F. (2001): Sociedades y territorios en riesgo, Ediciones del Serbal, Barcelona.

COQUE, R. (1984): Geomorfología, Alianza Editorial.

OLCINA CANTOS, J. y TORRES ALFOSEA, F.J. (1997): "Incidencia de los temporales de levante en la ordenación del litoral alicantino", en Papeles de Geografia de la Universidad de Murcia, 26, 109-136.

OLCINA CANTOS, J. (2007): Riesgo de inundaciones y ordenación del territorio en España, Instituto Euromediterráneo del Agua, Murcia.

ORTIZ, F.J., ARTECHE, J.L y SANZ, P. (2004): “Caracterización del oleaje en las aguas costeras del Cantábrico" en El clima, entre el mar y la montaña, IV Congreso de la Asociación Española de Climatología, Servicio de Publicaciones de la Universidad de Cantabria, Santander, 95-104.

SANJAUME SAUMELL, E. (1985): Las costas valencianas. Sedimentología y morfología, Tesis doctoral, Sección de Geografía, Universidad de Valencia, Valencia.

SELLÉS LÓPEZ, J.I. (1999): Estudio técnico y visual de playas: Costa Blanca 19971998, Escuela Politécnica Superior, Universidad de Alicante, Proyecto de fin de carrera (inédito).

TORRES ALFOSEA, F.J. (2002): "Riesgo y ordenación de los espacios litorales", en Ayala, F. y Olcina, J. (coords.), Riesgos naturales, Ariel, Barcelona, 1059-1083.

TORRES ALFOSEA, F.J. (2004): "El riesgo de temporales en el litoral de la provincia de Alicante", en Gil Olcina, A., Olcina Cantos, J. y Rico Amorós, A. (eds.), Aguaceros, aguaduchos e inundaciones en áreas urbanas alicantinas, Servicio de Publicaciones de la Universidad de Alicante, Alicante, 145-198.

TROS-DE-ILARDUYA FERNÁNDEZ, M. (2008a): Incidencia de los temporales maritimos en el litoral de la provincia de Alicante. Políticas de actuación en materia de Ordenación del Territorio. Tesis doctoral inédita. Instituto Universitario de Geografía, Universidad de Alicante.

TROS-DE-ILARDUYA FERNÁNDEZ, M. (2008b): “El reto de la Gestión Integrada de las Zonas Costeras (GIZC) en la Unión Europea", en Boletín de la Asociación de Geógrafos Españoles, 47, 143-156.

VERA, J.F. y OLCINA, J. (2002): "Riesgos naturales en la costa", en O.P. Ingeniería y Territorio, 61, 50-59. 


\section{RECURSOS ELECTRÓNICOS}

ERANS, S. et alii. Posicost: Seguimiento de playas y praderas de Posidonia oceanica. [En línea]. <http://www.imedea.uib.es/oceanography/html/events/vi_jornadas/HTML/pdf_5/119.pdf>. [4 de junio de 2003].

IMEDEA, Posicost-Estudio de la Posidonia oceanica y su interacción con la circulación costera y los procesos litorales en la costa balear y valenciana. [En línea]. $<$ http://www.imedea.uib.es/Oceanography/html/research/Projects/posicost/doc/ prensa.PDF $>$. [4 de junio de 2003].

MEDINA, J.R., Posidonia oceánica y regeneración de playas. [En línea]. <http:// elmundo.eldia.com/2002/03/17/illes_balears/1016233214.html>. 17 de marzo de 2002. Actualizado a las 23:48. [2 de abril de 2002].

WWW/ADENA. Las praderas de Posidonia: importancia y conservación. Propuesta de WWF/Adena. 2000. [En línea]. <http://www.wwf.es/descarga/informe_posidonia.pdf $>$. [10 de junio de 2003]. 